\title{
The impact of a workplace catering initiative on dietary intakes of salt and other nutrients: a pilot study
}

F Geaney*, J Harrington, AP Fitzgerald and IJ Perry

Department of Epidemiology and Public Health, University College Cork, Room 2.62, Brookfield Health Sciences

Complex, College Road, Cork, Republic of Ireland

Submitted 18 May 2010: Accepted 1 November 2010: First published online 18 January 2011

\begin{abstract}
Objective: Owing to modern lifestyles, individuals are dependent on out-of-home eating. The catering sector can have a pivotal role in influencing our food choices. The objective of the present study was to examine the impact of a structured catering initiative on food choices in a public sector workplace setting.

Design: A cross-sectional comparison study in two hospitals, one of which had implemented a catering initiative designed to provide nutritious food while reducing sugar, fat and salt intakes.

Setting: Two public sector hospitals in Cork, Ireland.

Subjects: A total of 100 random participants aged 18-64 years (fifty intervention, fifty non-intervention) who consumed at least one main meal in the hospital staff canteen daily. Each respondent was asked to complete one anonymous $24 \mathrm{~h}$ dietary recall and questionnaire. Food and nutrient analysis was conducted using WISP (Weighed Intake Software Program).

Results: Reported mean intakes of total sugars $(P<0 \cdot 001)$, total fat $(P<0 \cdot 000)$, saturated fat $(P<0 \cdot 000)$ and salt $(P<0 \cdot 046)$ were significantly lower in the intervention hospital when adjusted for age and gender. In the intervention hospital, $72 \%$ of respondents, compared with $42 \%$ in the non-intervention hospital, complied with the recommended under-3 daily servings of food high in fat and sugar $(P<0 \cdot 005)$. In the intervention hospital, $43 \%$ of respondents exceeded the recommended salt intake of $4-6 \mathrm{~g} / \mathrm{d}$, compared with $57 \%$ in the non-intervention hospital.

Conclusions: Structured catering initiatives in the workplace are a potentially important option in the promotion of healthy food choices. Targeted public health programmes and health policy changes are needed to motivate caterers in the public sector and other industries to develop interventions that promote a healthy diet.
\end{abstract}

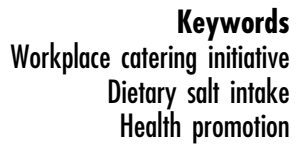

Diet and nutrition are important determinants of health and longevity. There is now a clear scientific consensus on the role of diet in the prevention of chronic diseases and major causes of death, including CVD, type 2 diabetes and specific causes of cancer ${ }^{(1)}$. There is increasing evidence that the catering sector can have a pivotal role in influencing our food choices ${ }^{(2)}$. In Ireland, mortality rates from CHD remain among the highest in Europe ${ }^{(3)}$. Approximately $35 \%$ of deaths are due to $\mathrm{CVD}^{(4)}$. In the context of CVD prevention, there is currently a significant focus on the need to reduce dietary salt intake because of the evidence of a causal role of salt in the aetiology of hypertension and $\mathrm{CVD}^{(5)}$ and the opportunity to achieve population-wide reductions in salt intake through collaboration with food processors and the catering sector. For instance, in the USA, it is estimated that a reduction in average dietary salt intake of $3 \mathrm{~g} / \mathrm{d}$ would reduce the annual number of incident $\mathrm{CHD}$ cases by 60000-120000, stroke by 32000-66000 and myocardial infarction by $54000-99000$, and reduce the annual number of deaths from any cause by $44000-92000$. It was also estimated that a regulatory intervention designed to achieve a reduction in salt intake of $3 \mathrm{~g} / \mathrm{d}$ would produce a saving of 194000-392000 quality-adjusted life-years and \$US10-24 billion in health-care costs annually ${ }^{(5)}$.

Workplace health promotion has been associated with a reduction in health risks ${ }^{(6)}$. In Western countries, it is recognised that employees are increasingly relying on their workplace to provide many of their daily meals, in particular breakfast and lunch ${ }^{(7)}$. Thus, workplace catering arrangements can have the potential to influence food consumption choices ${ }^{(8)}$.

Workplace dietary interventions have included positive measures to influence food choice such as price reductions 
on healthy options and increasing the access and appeal of healthy food ${ }^{(9)}$. In a '6-a-Day' Work-site Canteen Model Study in Denmark, it was reported that employees' total consumption of fruit and vegetables significantly increased when strategies were used by caterers to create appealing meals that were rich in fruit and vegetables. These strategies included mixing fruit and vegetables in rice, pasta and mashed potatoes, increasing the serving size of vegetable accompaniments and thickening sauces and soups with puréed vegetables ${ }^{(10)}$.

Data are limited on catering interventions designed to promote healthy food choices in the public sector. The aim of the present study was to examine dietary intakes in a cross-sectional comparison study involving staff in two hospitals, one of which has implemented a catering initiative focused on reducing dietary salt intake since 2007.

\section{Methods}

\section{General study design}

The present study was a cross-sectional comparison study of salt and dietary intakes in a representative sample of adults aged 18-64 years working in two public sector hospitals: one with the catering initiative (intervention) and one without a specific catering initiative (non-intervention).

\section{The intervention}

The focus of the catering initiative was to provide nutritious food options for staff, with particular focus on reducing salt intake. In 2007, the caterers implemented changes such as restriction of food high in salt, fat and sugar. All menus were modified to ensure that the healthiest option was available for patients and staff. Purchasing orders for high-salt products (gravy mixes, stock cubes) and processed meat (bacon, corned beef) were replaced with low-salt options (turkey, chicken and fish). Fresh herbs, spices and garlic were introduced to develop additional flavour. Salt was removed in all cooking processes. In the staff canteen, salt was removed from the tables but small salt sachets were available at service. Nutrition information on salt reduction and a healthy diet was displayed in the canteen area. No sauces or accompaniments were added to any meals without the customer's consent. Staff members were encouraged to consume extra salad and vegetable options with no extra cost. Cooking methods with oil were limited. All desserts were fruit-based. The non-intervention hospital did not follow a specific catering initiative. In the non-intervention hospital, both healthy and unhealthy options were available from the staff canteen.

\section{Subjects}

A random sample of 100 individuals took part in the study (fifty staff from each hospital). Individuals were eligible for the study if they consumed at least one main meal in the hospital staff canteen daily. Individuals were approached consecutively at the cash register in the staff canteen during lunch and dinner breaks (12.30-14.00 hours) after they had made their food choice and asked to participate in the study by the research assistant. In the intervention hospital, all individuals who were asked to participate agreed. Less than five in the non-intervention hospital refused to participate in the study.

\section{Data collection}

All respondents were asked to participate in the study during the time of meal consumption (12.30-14.00 hours). Participants were asked to complete one anonymous $24 \mathrm{~h}$ dietary recall and a questionnaire.

The questionnaire was self-completed by each participant before the $24 \mathrm{~h}$ dietary recall. The questionnaire was an adapted version previously used as a survey for health service staff ${ }^{(11)}$. The questionnaire consisted of sixteen questions, divided into four sections: demographic (gender, age); work environment (category of work, job security, job arrangement and hours of work); dietary perceptions (self-rated health, general dietary habits in the past year, salt dietary habits); and eating habits at work (dietary habits at work, salt intake at work).

The $24 \mathrm{~h}$ dietary recalls were completed with the aid of the researcher using a standardised method. The research assistant observed the participant's meal choice and recorded it. The participant was asked by the research assistant to recall their dietary intake for the previous $24 \mathrm{~h}$. Each data collection took approximately $30 \mathrm{~min}$. An alternative time was arranged between the participant and researcher if the mealtime was inconvenient.

\section{Food analysis}

Each 24 h dietary recall data entry was compared with the recommended servings of the Irish Food Pyramid. For the general adult population, the Irish Food Pyramid recommends that six or more servings of cereals, bread, potatoes, rice and pasta, five or more servings of fruit and vegetables, three servings of milk, cheese and yoghurt and two servings of meat, fish, poultry and alternatives be consumed daily. It is recommended that less than three servings of food high in fat and sugar (e.g. oils, butter and cakes) be consumed daily ${ }^{(12)}$.

Food and nutrient analysis was conducted using WISP ${ }^{\complement}$ (Weighed Intake Software Program; Tinuviel Software, Warrington, UK). WISP uses data from McCance \& Widdowson's The Composition of Foods ${ }^{(13)}$, plus supplemental volumes, to generate nutrient intake data ${ }^{(14-16)}$. Mean intakes of food energy, micro- and macronutrients, salt, saturated fat and total sugars were calculated.

\section{Statistical analysis}

Data were recorded manually and entered electronically into the Statistical Package for the Social Sciences statistical software package version $15 \cdot 0$ for Windows ${ }^{\mathrm{TM}}$ 
Table 1 Mean food and nutrient intakes in the intervention and non-intervention hospitals adjusted for age and gender

\begin{tabular}{|c|c|c|c|c|c|c|c|}
\hline & \multicolumn{2}{|c|}{ Intervention } & \multicolumn{2}{|c|}{ Non-intervention } & \multicolumn{2}{|c|}{ Difference } & \multirow[b]{2}{*}{$P$ value } \\
\hline & Mean & SD & Mean & SD & Mean* & $95 \% \mathrm{Cl}$ & \\
\hline Food energy intake $(\mathrm{kcal} / \mathrm{d})+$ & $1628 \cdot 6$ & $406 \cdot 3$ & 1900 & $450 \cdot 8$ & $298 \cdot 7$ & $126 \cdot 3,471 \cdot 1$ & 0.001 \\
\hline Total sugars $(\mathrm{g} / \mathrm{d})$ & $68 \cdot 7$ & $34 \cdot 2$ & 89.5 & $36 \cdot 2$ & $25 \cdot 27$ & $10 \cdot 67,39 \cdot 87$ & 0.001 \\
\hline Sucrose $(g / d)$ & $31 \cdot 3$ & $18 \cdot 9$ & $34 \cdot 6$ & $20 \cdot 4$ & 0.969 & $-7 \cdot 05,8.99$ & $0 \cdot 811$ \\
\hline Fructose (g/d) & $10 \cdot 8$ & $8 \cdot 3$ & $13 \cdot 2$ & $8 \cdot 5$ & $2 \cdot 7$ & $-0 \cdot 8,6 \cdot 12$ & $0 \cdot 131$ \\
\hline Total fat $(\mathrm{g} / \mathrm{d})$ & $60 \cdot 5$ & $22 \cdot 5$ & $83 \cdot 9$ & $30 \cdot 4$ & $23 \cdot 4$ & $12 \cdot 69,34 \cdot 2$ & 0.000 \\
\hline Saturated fat $(g / d)$ & $20 \cdot 7$ & $10 \cdot 1$ & $31 \cdot 9$ & $14 \cdot 0$ & $11 \cdot 4$ & $6 \cdot 45,16 \cdot 39$ & 0.000 \\
\hline Protein $(\mathrm{g} / \mathrm{d})$ & $79 \cdot 8$ & $18 \cdot 9$ & $83 \cdot 0$ & $22 \cdot 0$ & 5.9 & $-2 \cdot 124,13 \cdot 9$ & $0 \cdot 148$ \\
\hline Carbohydrates (g/d) & $204 \cdot 2$ & $61 \cdot 3$ & $215 \cdot 6$ & $50 \cdot 9$ & $15 \cdot 5$ & $-7 \cdot 95,38 \cdot 95$ & $0 \cdot 193$ \\
\hline Salt $(g / d)$ & $5 \cdot 6$ & $2 \cdot 7$ & $6 \cdot 7$ & $2 \cdot 9$ & $1 \cdot 04$ & $0 \cdot 21,2 \cdot 06$ & 0.046 \\
\hline $\mathrm{K}(\mathrm{mg} / \mathrm{d})$ & $2815 \cdot 2$ & $853 \cdot 2$ & $2983 \cdot 3$ & $835 \cdot 5$ & $300 \cdot 1$ & $-41 \cdot 65,641 \cdot 8$ & 0.085 \\
\hline $\mathrm{Ca}(\mathrm{mg} / \mathrm{d})$ & $664 \cdot 8$ & $299 \cdot 5$ & $855 \cdot 5$ & $320 \cdot 6$ & $223 \cdot 3$ & $94 \cdot 18,352 \cdot 4$ & 0.001 \\
\hline $\mathrm{Fe}(\mathrm{mg} / \mathrm{d})$ & $9 \cdot 4$ & $2 \cdot 9$ & $10 \cdot 0$ & $3 \cdot 6$ & 0.693 & $-0 \cdot 622,2 \cdot 13$ & $0 \cdot 280$ \\
\hline Vitamin $B_{6}(\mathrm{mg} / \mathrm{d})$ & $2 \cdot 4$ & $0 \cdot 68$ & $2 \cdot 3$ & $0 \cdot 66$ & $0 \cdot 18$ & $-0.25,0.29$ & 0.895 \\
\hline Vitamin $B_{12}(\mathrm{mg} / \mathrm{d})$ & $4 \cdot 5$ & $2 \cdot 5$ & $4 \cdot 2$ & $2 \cdot 1$ & -0.209 & $-1 \cdot 18,0 \cdot 76$ & 0.670 \\
\hline Vitamin $C(\mathrm{mg} / \mathrm{d})$ & $84 \cdot 5$ & $72 \cdot 6$ & $92 \cdot 4$ & $53 \cdot 1$ & $12 \cdot 35$ & $-13 \cdot 17,37 \cdot 88$ & 0.339 \\
\hline Vitamin D $(\mu \mathrm{g} / \mathrm{d})$ & $3 \cdot 6$ & $3 \cdot 1$ & 2.5 & $2 \cdot 5$ & -0.993 & $-2 \cdot 19,2.06$ & $0 \cdot 103$ \\
\hline
\end{tabular}

${ }^{*}$ Adjusted for age and gender.

$+1 \mathrm{kcal}=4 \cdot 184 \mathrm{~kJ}$.

(SPSS Inc., Chicago, IL, USA) before statistical analysis. Data manipulation and statistical analyses were conducted using the SPSS program. Proportions in the intervention and non-intervention hospitals were compared using Pearson's $\chi^{2}$ analysis. Mean levels of macronutrients, fibre, salt, fruit and vegetable intakes in the intervention and nonintervention hospitals were compared and evaluated using independent sample $t$ tests. A linear regression model was used to allow for the potential confounding effects of age and gender.

\section{Ethical approval}

The Social Research Ethics Committee in University College Cork approved the study. Permission was granted for the study by the chief executives and catering officers in both hospitals.

\section{Results}

The gender distribution in both hospitals was broadly similar. More women participated in the study (intervention: 74\%, non-intervention: $80 \%$ ). The intervention hospital had fewer younger respondents (aged 18-44 years: $50 \%$ ) in comparison with the non-intervention hospital (aged 18-44 years: 78\%). In both hospitals, respondents were working in permanent (intervention: $92 \%$, non-intervention: 78\%), full-time (intervention: $70 \%$, non-intervention: $76 \%$ ) and day-time (up to $8 \mathrm{~h}$ ) positions (intervention: 74\%, non-intervention: 86\%). The majority of respondents in the intervention hospital worked in management/administration (32\%) and nursing $(26 \%)$ categories. In the non-intervention hospital, most respondents held management/administration (50\%) and allied health professional (20\%) roles.

Compliance with the Irish Food Pyramid was examined. Significantly, $72 \%$ of respondents in the intervention hospital, compared with $42 \%$ in the non-intervention hospital, complied with the recommended under- 3 daily servings of food high in fat and sugar (e.g. oils, butter and cakes; $P<0 \cdot 005)$. Respondents in the intervention hospital were more likely to comply with the recommended six or more servings of cereals, bread and potatoes. However, more respondents in the non-intervention hospital consumed the recommended servings for meat, fish, poultry and alternatives (two servings), milk, cheese and yoghurt (three servings), fruit and vegetables (five or more servings). This may reflect the higher energy intake in the nonintervention hospital as shown in Table $1(P<0 \cdot 001)$.

Table 1 shows a breakdown of nutrient intake adjusted for age and gender in the intervention and non-intervention hospitals. Overall mean intakes were significantly lower for total sugars $(P<0 \cdot 001)$, total fat $(P<0 \cdot 000)$, saturated fat $(P<0.000)$ and salt $(P<0.046)$ in the intervention hospital compared with the non-intervention hospital. The mean salt intake in the intervention hospital $(5.6 \mathrm{~g} / \mathrm{d})$ did not exceed the recommended $6 \mathrm{~g} / \mathrm{d}$, compared with a mean salt intake of $6.7 \mathrm{~g} / \mathrm{d}$ in the non-intervention hospital. Respondents in the nonintervention hospital were significantly more likely to reach the RDA for $\mathrm{Ca}, 800 \mathrm{mg} / \mathrm{d}(P<0 \cdot 001)$. Respondents in the non-intervention hospital had a higher Fe intake but not significantly so. Respondents in both hospitals successfully reached the RDA for vitamins $\mathrm{B}_{6}, \mathrm{~B}_{12}$ and vitamin $C$. Mean intakes for vitamin $\mathrm{D}$ fell within the lower limits of the recommended intake range in both hospitals (RDA $=0-10 \mu \mathrm{g} / \mathrm{d}$ ).

The pattern of discretionary salt intake was also analysed. A total of $63 \%$ of respondents self-reported 'rarely/ never' using salt while cooking in the intervention hospital compared with $45 \%$ in the non-intervention hospital. In the intervention hospital, $56 \%$ respondents self-reported 'rarely/never' using salt at the table compared with $50 \%$ in the non-intervention hospital. 


\section{Discussion}

In this small observational study, we have shown that a structured catering initiative in a public sector setting has potential to reduce dietary intakes of salt, fat and sugar. It was noteworthy that the energy intake was also lower in the intervention hospital. This reflects the lower dietary intakes of total sugars and saturated fat in the intervention hospital. More respondents in the non-intervention hospital were exceeding dietary salt intake guidelines. It should be noted that the majority of staff were working in $8 \mathrm{~h}$ shifts; therefore, not all meals within the $24 \mathrm{~h}$ period were consumed in the hospital. This suggests that there may be some carryover from the workplace to the home environment. However, it should also be noted that respondents in the intervention hospital had lower $\mathrm{Ca}$ and Fe intakes. This highlights the need to consider both positive and negative impacts of workplace catering initiatives designed to promote a healthy diet.

The present study has a number of limitations, including the use of a cross-sectional as opposed to a longitudinal study design, lack of baseline measurements and data on potential confounders such as smoking and alcohol, and reliance on a single $24 \mathrm{~h}$ dietary recall to assess dietary intakes. Thus, inference on the impact of this catering initiative must be tentative. In particular, it may be suggested that the findings are due to reverse causation; that is, the selection of a workplace restaurant offering healthy choices by more health-conscious staff. However, staff in this workplace do not have a choice of restaurants and are unlikely to eat off campus because of the lack of alternative restaurants within a reasonable distance from the campus. Although the $24 \mathrm{~h}$ dietary recall method is an efficient method of data collection, with little burden on participants, it will be important in future work to obtain multiple $24 \mathrm{~h}$ dietary recalls, including weekday and off-duty periods, to assess potential carryover from the workplace to the home and other settings.

The reference method for analysing dietary salt intake is $24 \mathrm{~h}$ urinary $\mathrm{Na}$. Approximately $95 \%$ of dietary $\mathrm{Na}$ is excreted through the urine, with minimal losses in sweat and faeces ${ }^{(17)}$. In further work on the impact of catering interventions, data on $24 \mathrm{~h}$ urinary $\mathrm{Na}$ excretion would be invaluable. It will also be important in future work to obtain good data on smoking, alcohol and work environment, given the effect of these confounders on dietary choices ${ }^{(18)}$.

The present study complements and extends the findings from other worksite nutrition interventions. A study in Finland showed that a worksite vegan nutrition programme influenced nutrient intake when caterers produced low-fat vegan options, combined with nutrition education and support in the form of a dietitian, cooking instructor and a physician. They reported an increased intake of protective factors such as folate, vitamin $\mathrm{C}$ and fibre and decreased intakes of total fat, saturated fat and cholesterol $^{(19)}$. The present study provides evidence that nutrition interventions can influence food at work. In particular, the study findings suggest that a structured catering initiative sustained over a relatively long period (2 years in this instance) may produce long-term positive effects on food choices at work and at home. Important stakeholders such as the catering management, chefs and advisory committees (nutritionist, dietitian) can promote the maintenance of a catering initiative in the workplace through organisation, teamwork and ongoing evaluation. However, there is a clear need to extend these preliminary findings in large-scale intervention studies to a range of workplace settings.

\section{Conclusion}

In summary, the findings from the present study suggest that the workplace can be a supportive and influential environment in the promotion of a healthy diet. In many countries worldwide, the public sector is a major employer with significant opportunities to promote healthy diets in the workplace. There is a need for large-scale intervention studies in a wide range of public sector settings to provide the evidence base for policy in this area.

\section{Acknowledgements}

The present research was supported by the HRB Centre for Health \& Diet Research which is funded by the Irish Health Research Board and by the Department of Agriculture, Fisheries and Food. It was also supported by the catering departments in St Stephens Hospital and the South Infirmary. No conflict of interest was evident with the present research study. F.G. carried out the field research. She worked on the study design and statistical analysis. She had a primary responsibility for the final content of the paper and is the guarantor. J.H. and A.P.F. contributed to the data analysis and interpretation. I.J.P. was the principal investigator and COsupervisor of the study. He contributed to the study design, data analysis and interpretation of the study. He co-wrote the paper. All authors approved the final version of the paper for publication. The authors extend their sincere thanks to Ms Helena O' Brien, Catering Manager of St Stephens Hospital, PRO of Catering Management Association of Ireland.

\section{References}

1. Lachat C, Roberfroid D, Huybregts L et al. (2009) Incorporating the catering sector in nutrition policies of WHO European Region: is there a good recipe? Public Health Nutr 12, 316-324.

2. World Health Organization (2003) Diet, Nutrition and the Prevention of Chronic Diseases. Joint WHO/FAO Expert Consultation. WHO Technical Report Series no. 916. Geneva: WHO.

3. Bennett K, Kabir Z, Unal B et al. (2006) Explaining the recent decrease in coronary heart disease mortality rates in Ireland, 1985. J Epidemiol Commun Health 60, 322-327. 
4. Central Statistics Office (2009) Statistical Yearbook of Ireland 2009. Cork: CSO; available at http://wwwcsoie/ releasespublications/documents/statisticalyearbook/2009

5. Bibbins-Domingo $\mathrm{K}$, Chertow GM, Coxson PG et al. (2010) Projected effect of dietary salt reductions on future cardiovascular disease. $N$ Engl J Med 362, 590-599.

6. Addley K, McQuillan P \& Ruddle M (2001) Creating healthy workplaces in Northern Ireland: evaluation of a lifestyle and physical activity assessment programme. Oсcup Med (Lond) 51, 439-449.

7. Wanjek C (2005) Food at Work: Workplace Solutions for Malnutrition, Obesity and Chronic Diseases. Geneva: International Labour Organization.

8. Roos E, Sarlio-Lähteenkorva S \& Lallukka T (2004) Having lunch at a staff canteen is associated with recommended food habits. Public Health Nutr 7, 53-61.

9. Luzzi AF, Gibney M \& Sjostrom M (2001) Nutrition and diet for healthy lifestyles in Europe: the Eurodiet evidence. Public Health Nutr 4, 437-438.

10. Lassen A, Thorsen AV, Trolle E et al. (2004) Successful strategies to increase the consumption of fruits and vegetables: results from the Danish (6 a day) Work-site Canteen Model Study. Public Health Nutr 7, 263-270.

11. Harrington J (editor) (2003) The Survey of Food and Healthy Eating Practices amongst Staff of the Western Health Board. Galway: Community Nutrition and Dietetic Services Western Health Board.

12. Harrington J, Perry I, Lutomski J et al. (2008) SLÁN 2007: Survey of Lifestyle, Attitudes \& Nutrition in Ireland. Dietary
Habits of the Irish Population, Department of Health and Children. Dublin: The Stationery Office.

13. Holland BWA, Unwin ID, Buss DH et al. (1995) McCance E Widdowson's The Composition of Foods, 5th ed. London: Royal Society of Chemistry and Ministry of Agriculture, Fisheries and Food/HMSO.

14. Chan W, Brown J \& Buss DH (1994) Miscellaneous Foods. Fourth Supplement to McCance \& Widdowson's The Composition of Foods, 5th ed. Cambridge and London: The Royal Society of Chemistry and the Ministry of Agriculture Fisheries and Food.

15. Chan W, Brown J, Lee SM et al. (1995) Meat, Poultry and Game. Fifth Supplement of McCance \& Widdowson's The Composition of Foods, 5th ed. Cambridge and London: The Royal Society of Chemistry and Ministry of Agriculture Fisheries and Food.

16. Chan W, Brown J, Church SM et al. (1996) Meat Products and Dishes. Sixth Supplement of McCance \& Widdowson's The Composition of Foods, 5th ed. Cambridge and London: The Royal Society of Chemistry and Ministry of Agriculture Fisheries and Food.

17. Liu K \& Stamler J (1984) Assessment of sodium intake in epidemiological studies on blood pressure. Ann Clin Res 16, 49-54.

18. Padrão P, Lunet N, Santos A et al. (2007) Smoking, alcohol, and dietary choices: evidence from the Portuguese National Health Survey. BMC Public Health 7, 138.

19. Levin S (1996) Pilot study of a cafeteria program relying primarily on symbols to promote healthy choices. $J$ Nutr Educ Behav 28, 282-285. 